مجلة جامعة سبها للعلوم البحتة والتطبيقية

Sebha University Journal of Pure \& Applied Sciences

Journal homepage: www.sebhau.edu.ly/journal/index.php/jopas

\title{
Chemical Engineering Graduate Courses Curriculum Development with Simulation Components
}

*Mohamed Edali ${ }^{\mathrm{a}, \mathrm{b}}$, Walid Alaswad ${ }^{\mathrm{a}}$, Ali Bseibsuª ${ }^{\mathrm{a}}$ Zaed Sahem ${ }^{\mathrm{b}}$, Faraj Ben Rajeb ${ }^{\mathrm{c}}$, Ali Elkamel ${ }^{\mathrm{d}}$

aDepartment of Chemical and Petroleum Engineering, Elmergib University, Elkhoms, Libya

bCreativity Group for Technical Services, Ottawa, Ontario, Canada

cDepartment of Oil and Gas Engineering, Memorial University, St. Johns, NL, Canada

dDepartment of Chemical Engineering, University of Waterloo, Waterloo, ON, Canada

\section{Keywords:}

Engineering Education

Engineering curriculum

Educational innovation "Computer

aided Multiphysics application

design tool" (COMSOL)

Inquiry-based learning (IBL)

Transport Phenomena

\begin{abstract}
A B S T R A C T
The graduate chemical engineering curriculum at our institution Elmergib University is replete with both problem-based and project-based learning components. This paper focuses on a complex methodology of inquiry-based learning (IBL), which has been proven to well prepare graduate students for a successful career in engineering. IBL requires Students to invest a considerable time during the class and after working at home learning with the aid of mentoring how to develop and answer a research question. Teaching both IBL and the development of field-specific simulation skills challenge professors. That does not allow much of the class time required to cover material reliance on mathematical tools that often hamper student understanding of the underlying phenomena and difficulty in providing immersive and exciting visuals that support in-depth learning. An IBL component was incorporated into a simulation-based design in four successive graduate courses: Advanced computational Numerical Methods, Advanced heat transfer, Advanced fluid mechanics, and Advanced transport phenomena. The courses were modified to contain Multiphysics simulations with application building that develop technical competency by developing modeling skills, deeper understanding by solving realistic problems, and writing skills by producing technical reports for each simulation. The use of the Multiphysics application building component adds a new skillset that further strengthens our program graduates. The paper shows the teaching and learning strategies efforts have been implemented, course teaching tools Apps structure, student outcome assessment, and research project exam questions and their simulation results from students' reports.
\end{abstract}

$$
\text { تطوير مناهج الدراسات العليا للهندسة الكيميائية بدمج مكونات المحاكاة }
$$

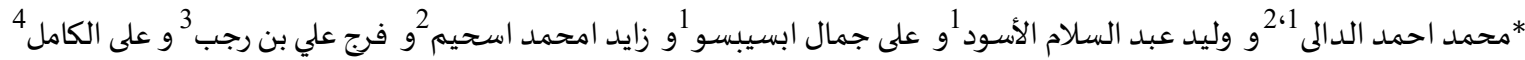

$$
\begin{aligned}
& 1 \text { قسم الهندسة الكيميائية والنفط، جامعة المرقب، الخمس، ليبيا }
\end{aligned}
$$

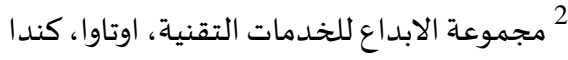

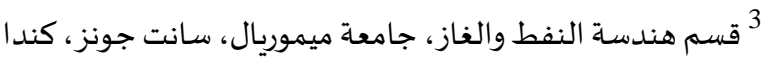

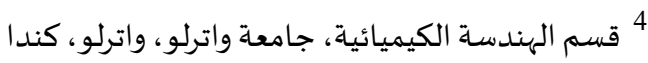

\begin{tabular}{|c|c|}
\hline الكلمات المفتاحية: المتات & الملخص اخص \\
\hline التعليم الهندسي & تم دعم منهج الدراسات العليا للهندسة الكيميائية بجامعة المرقب بمكونات التعلم القائمة على حل المشـاكل \\
\hline 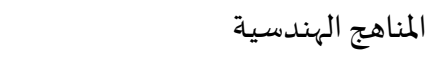 & والمشاريع الهندسية. تركز هذه الورقة على منهجية التعلم القائم على الاستفسار المعقدة (IBL)، والتي ثبت أهها \\
\hline "الابتكار التعليمي بمساعدة الحاسوب & تعد طلاب الدراسـات العليا بشكل جيد لمهن هندسية ناجحة. تتطلب منهجية (IBL) من الطلاب استثمار وقت \\
\hline بأداة تصيميم التطبيقات متعددة & كبير خلال فترة التواجد بالفصل وبعده كعمل منزلي للتعلم بمساعدة التوجيه وكيفية تطوير الإجابة على سؤال \\
\hline الفيزياء" (COMSOL) & البحث. تدريس كلا من (IBL) وتطوير مهارات المحاكاة الخاصة يمثل تحديات للأساتذة. وقت الفصل الدراسي \\
\hline ظو التع القائم على الاستفسار (IBL) & اللازم لتغطية التحليل الرياضي لا يسمح بالإفاضية ويعيق فهم الطلاب للظواهر الأسـاسية وصعوبة توفير صور \\
\hline
\end{tabular}

*Corresponding author:

E-mail addresses: dredalicreativitygroupts@gmail.com, (W. Alaswad) walaswadzo@gmail.com, (A. Bseibsu) ajbseibsu@elmergib.edu.ly, 


$$
\begin{aligned}
& \text { غامرة ومثيرة تدعم التعلم المتعمق. تم دمج مكون (IBL) في تصيميم قائم على المحاكاة في أربع مقررات دراسات }
\end{aligned}
$$

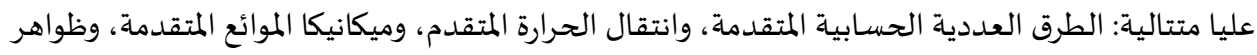

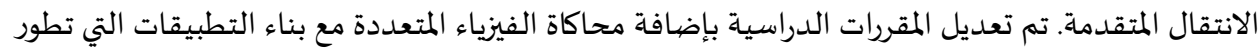

$$
\begin{aligned}
& \text { الكفاءة التدريسية التقنية من خلال تطوير مهارات النمذجاة، وفهم أعمق من خلال حل المشاكل الواقعية، }
\end{aligned}
$$

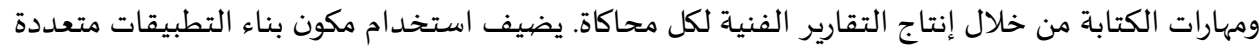

$$
\begin{aligned}
& \text { الفيزياء مجموعة مهارات جديدة تعزز خريجي برنامجنا. تظهر الورقة أن جهود استراتيجيات التعليم والتعلم قد مد مداء } \\
& \text { تم تنفيذها، وهيكلة تطبيقات أدوات التدريس، وتقييم نتائج الطلاب، وأسئلة امتحان المشروع البحثي ونتائج } \\
& \text { المحاكاة الخاصاة بها من تقارير الطلاب. }
\end{aligned}
$$

\section{Introduction}

The main objective of the master's program at the department of chemical engineering of Elmergib University is to refine the skills and research expertise of the graduate students by expanding their specialized knowledge of chemical engineering primarily achieved through course work, research seminars, and technical training. Academic teaching has been traditionally focused on the theoretical instructions delivered in classroom lectures. However, chemical engineering graduate program course tasks and their data processing and model evaluation are time-consuming. They are not adding much value to the student's learning experience as they reduce the available time for result analysis, critical thinking, and report writing skills development. In addition, a well-known issue is that processing experimental knowledge and examination of results against theoretical models are often time-consuming because of repetitive and complicated calculations. That holds back the student's available time for analysis and discussion resulting into a poor-quality report. Engineering graduates are facing an emerging class of design challenges that span multiple disciplines of science and technology. Sophisticated computational techniques, combining the representative physics of multiple domains, are needed to accurately model and predict results. Most engineering degree programs offer major specific modeling courses or embed simulations on a limited basis. For example, chemical engineering graduate students may be exposed to mass and heat modeling and computational fluid dynamics problems. Few engineering curricula, including those in our department, offer multi-physics design and research experiences. Where available, they are typically restricted to some term projects for post-graduate studies; consequently, most main graduate courses curricula have little or no exposure to areas of expertise outside their own discipline. This is inconsistent with the view that future graduates need to be more adaptable and versatile to succeed in the global marketplace [1].

The authors have developed a chemical engineering graduate course curriculum focused on the methods and techniques used in multidisciplinary modeling. Students become active participants by being challenged to solve a series of projects. Contextualized assignments are selected from high priority research topics. A broad recognition believes that meaningful learning in engineering requires that students master fundamental concepts, rather than the memorization of facts and formulas [2 - 3]. A problem domain that a student relates to and finds relevant leads to deeper understanding and a smoother transfer to other domains. Contextualized projects lead to a more enjoyable experience motivating students to work in a new way.

To be successful in a knowledge-based global workplace, an engineering graduate should have the ability to design complex systems of devices and components that perform in real-world conditions. In such problems, multiple sets of coupled physics often apply and interact in both space and time. Therefore, a robust model must span several disciplines to obtain a solution that can be experimentally validated.

One approach is to use numerical techniques in which the physical geometry is represented by a mesh of finite elements that collectively satisfy the relevant equations. To simplify development, the preferred approach is to employ a single solution builder to configure, constrain, solve, and post-process results. At times, multiple models, each with specific geometry, materials, constraints, and physics, may be used sequentially or co-exist and be coupled. As with all numerical methods, care must be taken to ensure proper convergence and accuracy of the result. Model creation typically proceeds along these lines: define problem steps including simplifying assumptions, identify global constants and expressions, construct physical geometry including symmetries, and specify domains and material properties. Other steps are needed to get model results, such as setting boundary conditions, meshing physical structure into finite elements, selecting physics for each domain, configure study types and initiate solver, and results can post-processed for more visualized forms.

Multiphysics software COMSOL can accelerate the timetable needed to create a working model. A family of graphical interfaces, organized in a tree structure, guides the development process while providing contextual help along the way. Geometries can be imported from leading computer-aided-drawing (CAD) packages. A properties library is embedded that covers many common materials. Meshing options include external file import and adaptive techniques where dynamic adjustments are made during the solving process. If necessary, users customize the physics further by adding additional algebraic expressions and partial differential equations. Authors of this comprehensive teaching philosophy paper based their findings and discussions on their three publications have been published throughout the teaching process for the last five years. In the teaching works in the heat transfer course Edali et al. [4], the transport phenomena course Sahem et al. [5], and the fluid mechanics course Edali et al. [6], authors applied COMSOL Multiphysics software and its new Apps application builder features throughout the teaching process to reach the main goals which were to maximizing the efficiency of the learning process. They found that in Engineering based courses, using simulation apps are helping to expand the investigation techniques while keeping students engaged to strike such a balance by introducing students to complex concepts in a simplified format.

\section{Experiential Courses Curriculum analysis}

The courses are three credits each and transpire over a 14-week semester. Each subject is taught in a computer laboratory with a maximum of 15 students. The teaching and learning strategies were developed by the authors who have advanced experience in the disciplines of chemical engineering and computer science. The following types of co-teaching are envisioned: lead and support, team, and alternative. Each course is currently being taught by one instructor at a time, while other options are being explored.

We now describe the course and student organizational context. In the authors' experience, experiential courses are very often overly reliant on assignments with predetermined results. Students are tasked to complete and document work where only correct and predictable outcomes are allowed.

The course design is based on teaching and learning strategies such as cooperative learning in teams of two, which builds competency in multidisciplinary modeling, contextualized by focusing on relevant 
topics, and Project-based assignments.

The first and Second strategies involve cooperative learning in which students work in teams of two. Culver et al. [7] and King et al. [8] showed that students mature most readily when teaching balances both a challenge and support. The Challenge incorporates repeated exposure to and synthesis of the legitimate uncertainties in knowledge and is supported by high quality mentoring. Studentcentered teaching that includes a rich combination of active and cooperative learning is advocated by Felder et al. [9-10]. Millis and Cottell [11] offer thorough and well-documented support for cooperative learning at the college level provided that students are trained. While in most courses there is insufficient time for training [12], by keeping the team members and assessment materials the same, students learn to effectively perform peer and self-evaluation [8].

The third strategy heightens motivation by selecting topics from high priority research areas. Interest is peaked as students become active participants in the analysis and discovery of relevant and important design problems.

The fourth strategy is to use project-based assignments, each containing a high level of hands-on activity. Assignments are organized into three modules: first, classical projects with prescribed outcomes, second, higher-level transitional projects, and third, a student-centric design of a model. This structure builds on existing skills and knowledge, connects them in a logical way and engages students in inquiry and learning, gradually developing competence. The process of multi-physics modeling and the user interfaces of the software application needs classical projects to familiarize students with. Teams following a set of procedures, construct working models, analyze results, and write formal reports. The learning outcomes associated with this module are to gain familiarity with the modeling development process, learn the graphical user interface, complete a modeling project from scratch, and document the results in a technical report. Transitional projects have defined objectives; however, some design elements are intentionally left out prompting students to synthesize a working model so that meaningful results can be acquired. Although the goal is clearly stated, the task of filling in the missing pieces is the challenge. The learning outcomes of this module are to discover missing modeling elements, research and incorporate relevant information, and synthesize a successful project, Justify, validate, and document the results. The design of a model is the culminating experience in which the students are required to integrate prior skills into an independent research initiative appropriate for the course. The learning outcomes of this module are to generate concepts and filter down to a single proposal, research and utilize relevant information, evaluate alternatives within the construct of the model, synthesize a design and generate a solution, manage the project within time constraints, formally document the findings, and deliver a formal oral presentation.

In summary, the course integrates four teaching and learning strategies in an innovative way. Project-based assignments focused on relevant research topics, are delivered using a scaffolding process and conducted in a cooperative learning environment.

\section{Results and Discussion}

The authors of this paper and their efforts throughout the last few years of renewing the curriculum of the core of postgraduate courses at the department of chemical engineering at Elmergib University proved that using simulation Apps to be an extremely useful tool for professors. They are concluding their detailed findings through teaching the advanced courses and collecting the student solution, documentation, presentations, and surveys that they can design systems more efficiently by reducing the required number of experiments. They also say that some of the main challenges in teaching postgraduate engineering courses lie in the newer domains and technologies, such as nanotechnologies and advanced biological systems. Professors, as well as students, would be greatly beneficial when simulations in these new and advanced courses have been introduced. The following representation of the four main advanced course teaching experiences will be concluded in a short description for each subject relying more on the figures, which were condensed to work as much representative as possible due to the limited allowed pages in this conference paper.

\section{Advanced Numerical Methods in Chemical Engineering Course}

This master's program course at the department of chemical engineering of Elmergib University is designed to have a google classroom as a learning management system (LMS), as in Fig. 1.

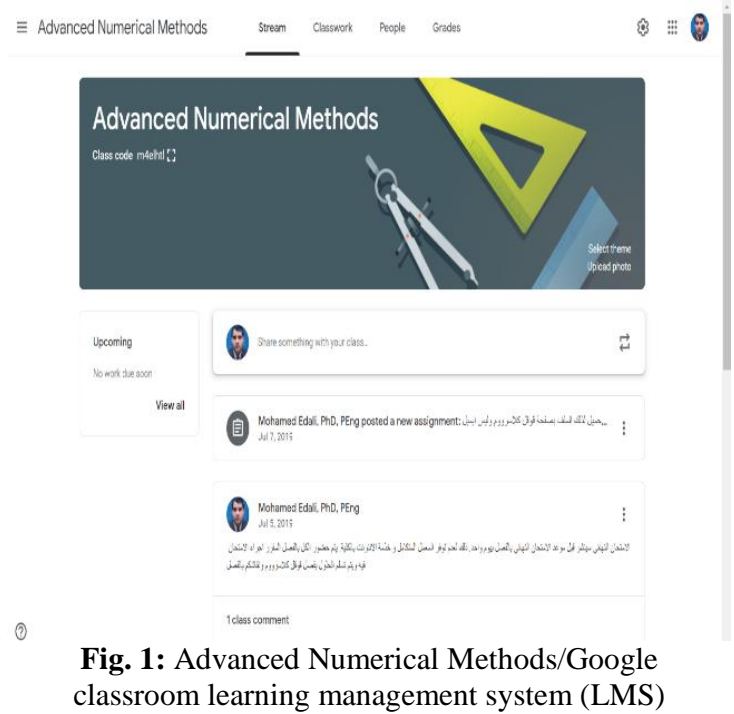

This LMS aims to engage students in learning online, simplify creating, distributing, handing their solved assignment and programmed model of exams and grading system in efficient ways. Today's Engineering educational curriculum is evolving at a faster pace than any other period in recent history's instruments and innovation.

The course objective is to spend the first few weeks on model development solving PDE' in programmed Excel sheets under the environment of visual basic. Different finite difference techniques to be followed and stability of the solution are assessed as can be seen in the course used teaching Apps in Fig. 2, and Fig. 3. The associated first exam demonstrated that the students had a satisfactory grasp of the principles of deriving ordinary and partial differential equations and their boundary conditions and were able to appreciate the physical situations to which they corresponded.

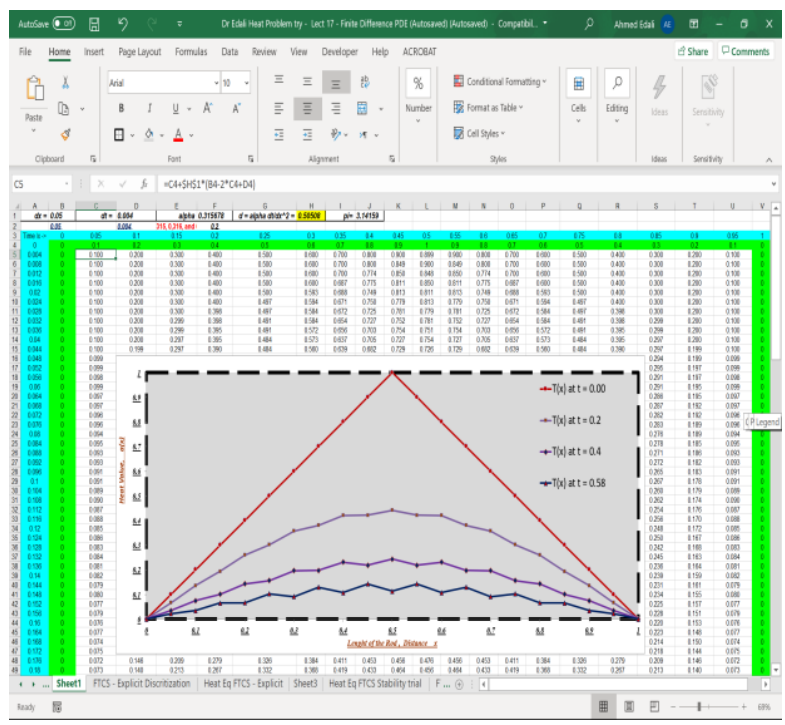

Fig. 2: Heat Transfer Numerical Problem by FTCS - Explicit App 1 


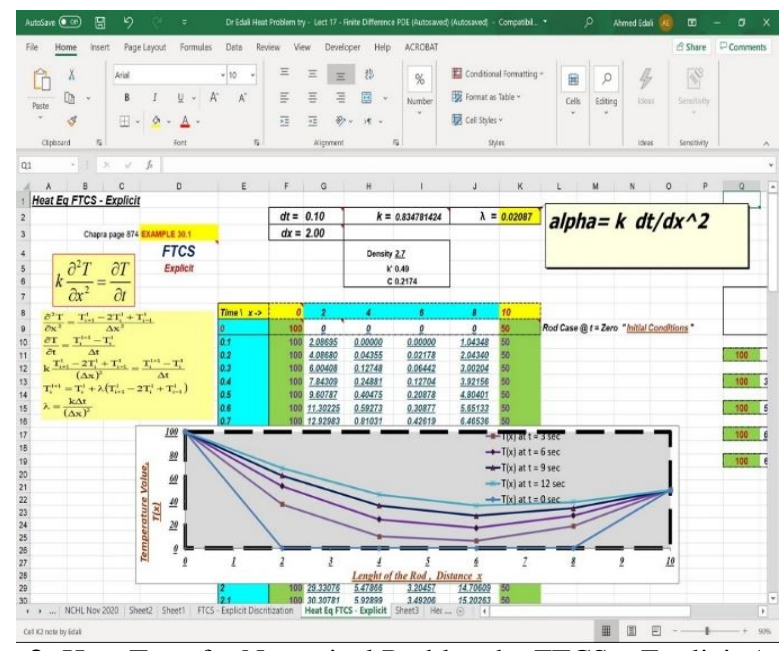

Fig. 3: Heat Transfer Numerical Problem by FTCS - Explicit App 2

The remainder of the course was directed towards the numerical solution of the equations using COMSOL which requires some background in mathematical topics that the students had not all seen before. Classes were explicitly provided for matrix manipulations and vector and tensor calculus. The lectures of the course cover the derivation and set-up of differential equation models for transport and reaction in chemical engineering. We cover lumped models, boundary-value problems, boundary conditions, elliptic Laplace equation PDEs, parabolic heat/diffusion equation PDEs, convection first-order PDEs and briefly mentioned wave equation hyperbolic PDEs. Instruction in using the COMSOL watch and do a methodbased program took place in a computer lab. Fortunately, the students nearly unanimously preferred to use COMSOL to solve the model project analysis based on final exam questions to the idea of returning to Excel and using finite differences, as can be noticed in Fig. 4, Fig. 5, and Fig. 6. The students' numerical responses and written comments indicated a strong degree of satisfaction with the course, feeling that they had learned useful material and become better computer users in an engineering context.

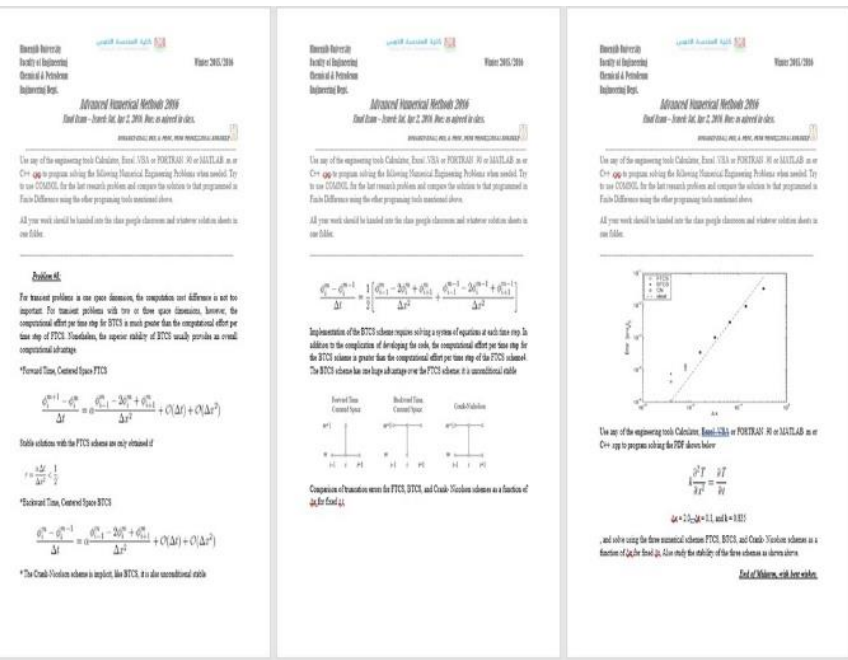

Fig. 4: Advance Numerical Methods Course Final Exam Research Problem

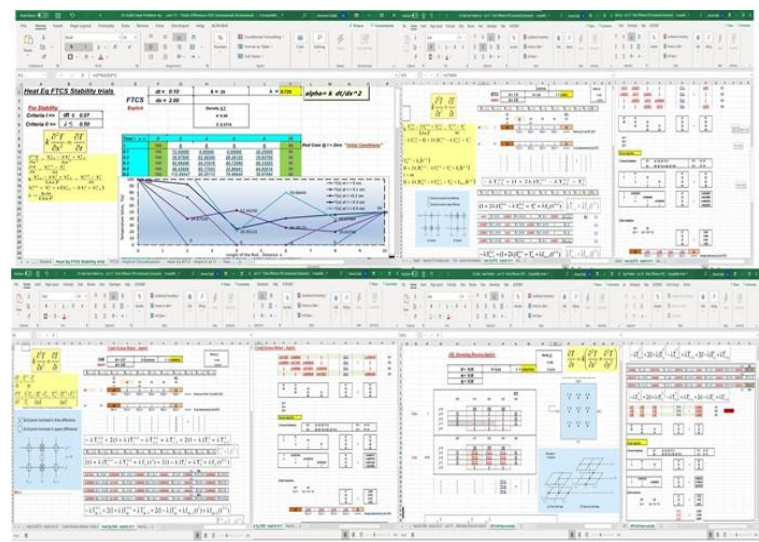

Fig. 5: Excel VBA App, to teach Finite Difference Techniques to solve a Parabolic PDE in FTCS, BTCS, Crank Nicholson, and ADI

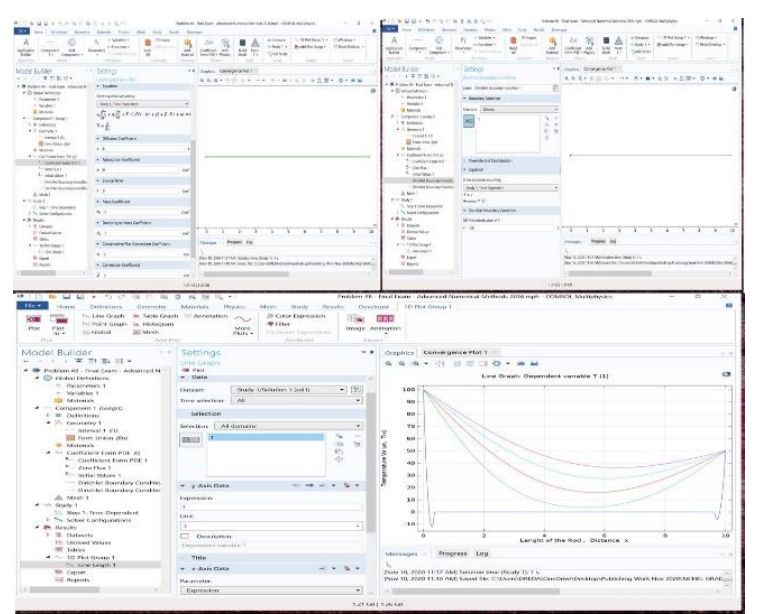

Fig. 6: Problem \#8 Student Solution - Final Exam - Advanced Numerical Methods 2016

\section{Advanced Heat Transfer in Chemical Engineering Course}

This course is designed to have a google classroom as a learning management system (LMS) as in Fig. 7, then lectures show how postgraduates are introduced to computational Heat Transfer in research projects. The students first solve problems in their textbook which is good at presenting the fundamentals, where most of the problems are one-dimensional since that is the limit of the mathematical ability of most postgraduates. Real-life examples motivate students, but they have limited time.

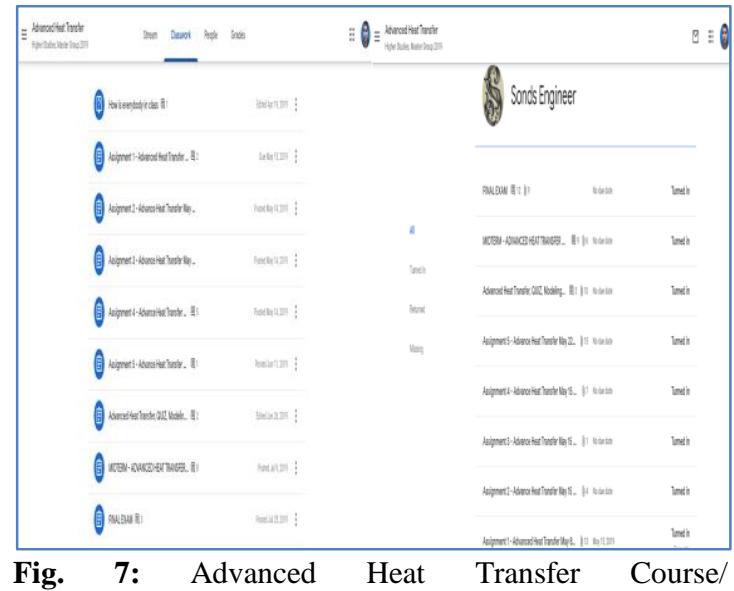

classroom learning management system (LMS)

With the advent of sophisticated software, however, it becomes possible for postgraduates to solve meaningful transport problems in two and three dimensions. This part presents the methods used to 
introduce postgraduates to COMSOL Multiphysics and the problems they solve in a research project format. First, students learn to solve problems in their textbooks and validate the solution with the use of course teaching Apps as in Fig. 8. This technique gives confidence that the computer program is solving the right equations. Next, they solve more complicated $2 \mathrm{D}$ problems by removing previous $1 \mathrm{D}$ assumptions, which go beyond their textbooks.
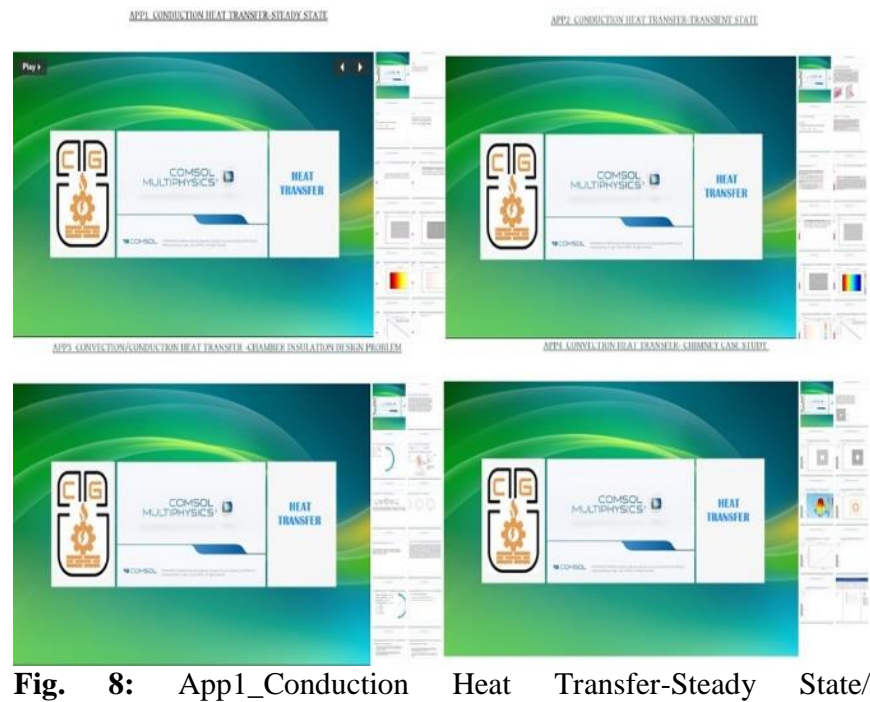

Fig. 8: App1_Conduction Heat Transfer-Steady State/ App2_Conduction Heat-Transfer- Transient State/ App3_Convection-Conduction Heat Transfer/ App4_Convection Heat Transfer

Students made to prove the necessity of solving the problem correctly using a computer program to estimate the numerical error even though there is no analytic solution. They learn how to investigate the accuracy of the solution by checking their data input to the program, mesh refinement and explore the many ways to analyze and view the results. Fig. 9 to Fig.14 show how-to for students to answer research problems in the final exam of the course following different teaching stages that occur throughout the course. Their solution reports produced include $1 \mathrm{D}$ hand derivation and compared to 2D solutions in detail to show the analysis techniques and then solve extensions to them by removing assumptions. A simple version of their ultimate problem to be solved to learn how to verify their solution and finally, they solve the research problem in full.

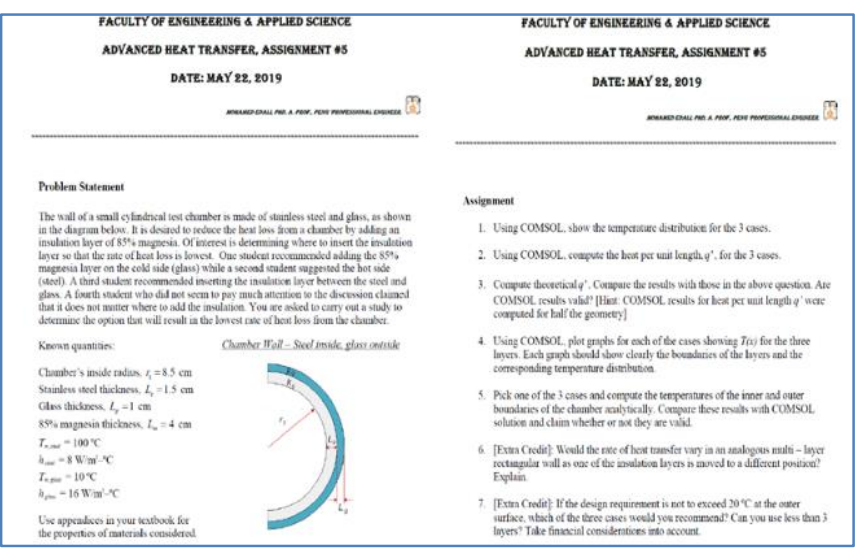

Fig. 9: Advanced Heat Transfer Course Final Exam Problem Statement and requested simulation work.

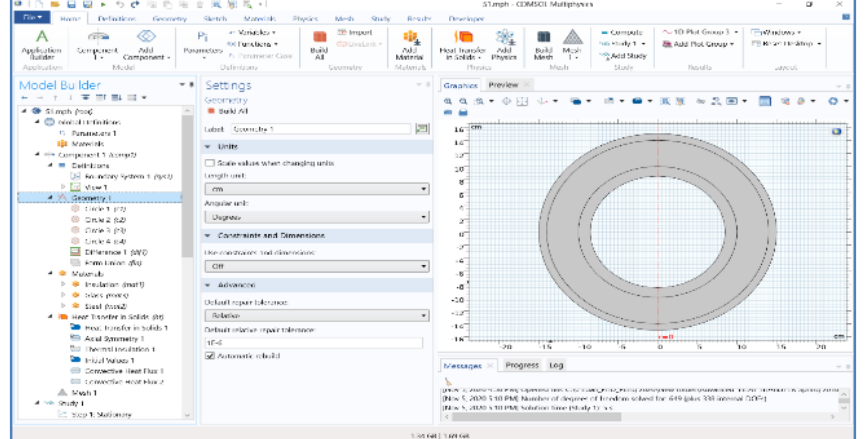

Fig. 10: COMSOL Model Student Solution for Final Exam design Problem, Geometry Setting

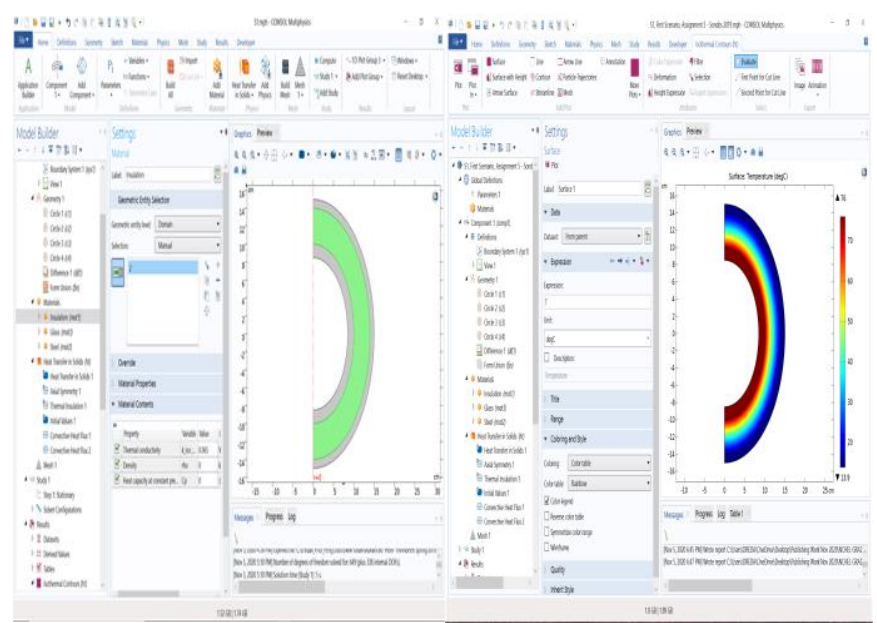

Fig. 11: COMSOL Model Student Solution for Final Exam design Problem, Design Scenarios, and Surface Temperature Distribution

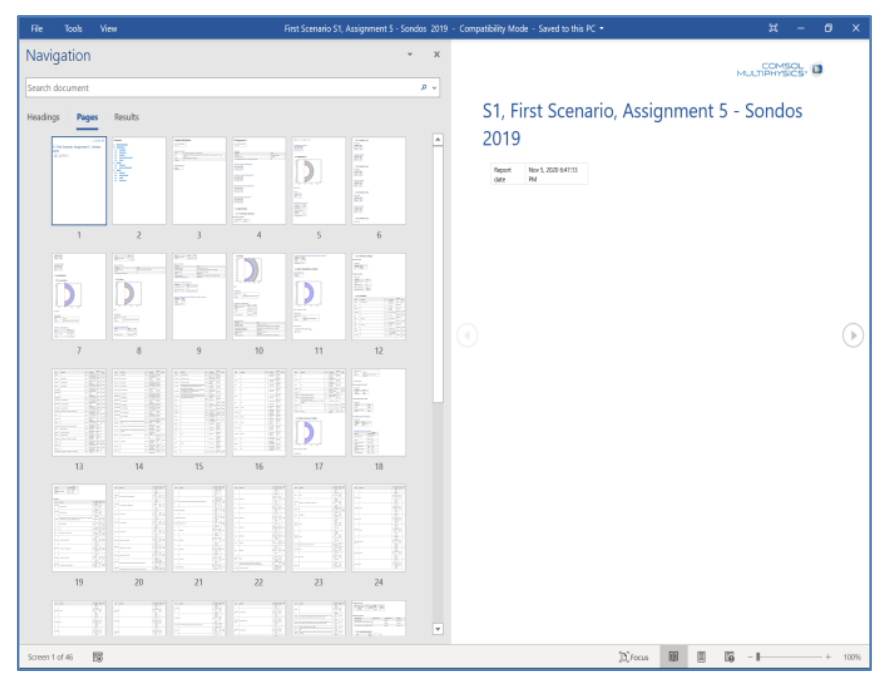

Fig. 12: COMSOL Model Student Solution for Final Exam design Problem Report 


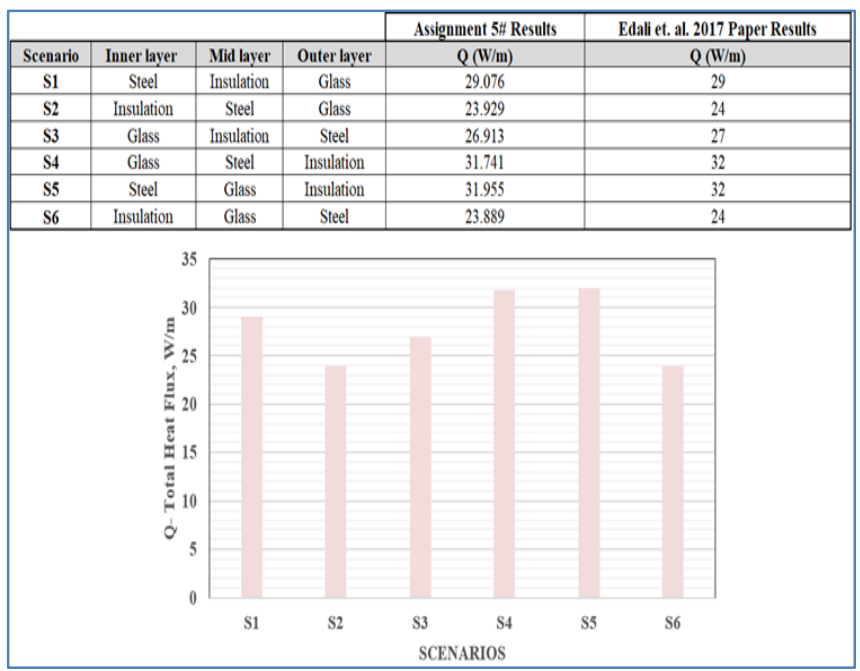

Fig. 13: Total Heat Flux Magnitude, Student work validation with [11] $(\mathrm{W} / \mathrm{m})$

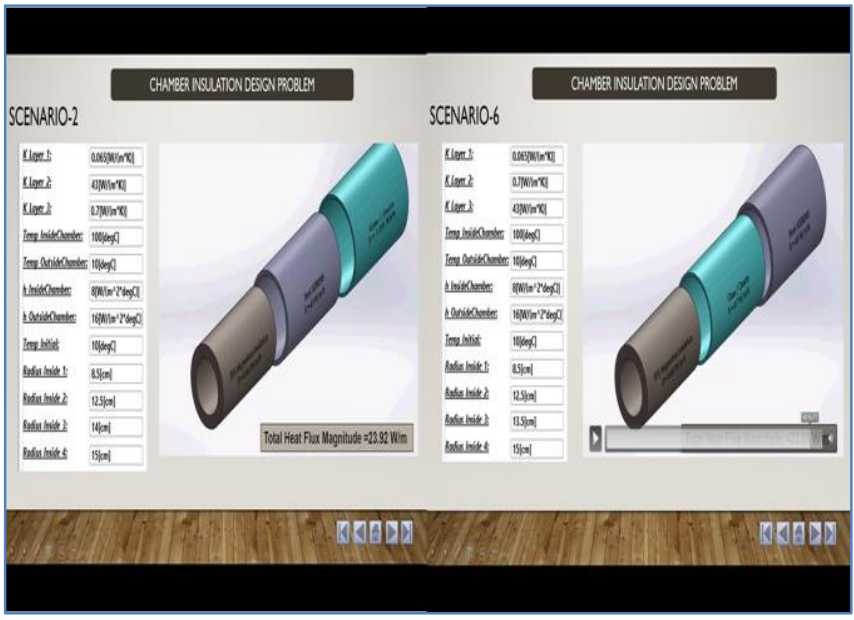

Fig. 14: App-3 Chamber Insulation Design Problem, Validation with [11].

\section{Advanced Fluid Mechanics in Chemical Engineering Course}

The Advanced Fluid Mechanics course is arranged to have a google classroom as a first step to register the students as a learning management system (LMS) as in Fig. 15.

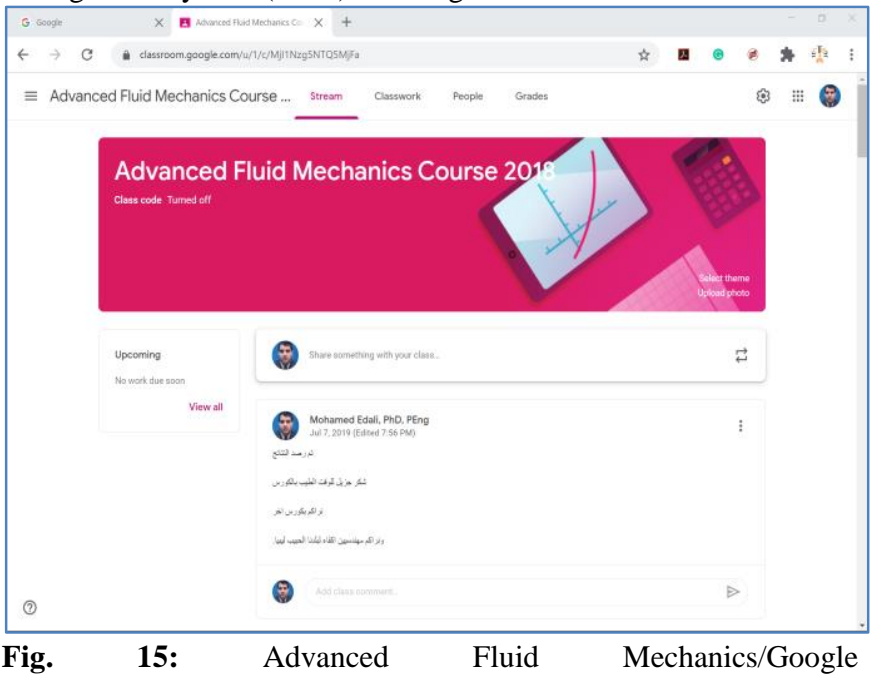

classroom learning management system (LMS).

Computational fluid dynamics, CFD fundamentals were introduced to this advanced course by implementing COMSOL software to teach fluid dynamics more effectively. In recent years, CFD has become an important part of fluid dynamics; however, postgraduate students at our department at Elmergib University have limited access to those new software techniques. In many engineering problems, simulation has become an essential step in designing and optimizing processes. Therefore, the COMSOL simulation Apps teaching project was assigned to be a teaching process as shown in Fig. 15. This paper presents a case study of a postgraduate advanced fluid dynamics project where students were challenged to design a shape, estimate different research models through the COMSOL Apps simulation tool. This teaching process techniques aimed to enhance the students to understand the use of simulation on the model testing where quizzes were assigned to evaluate the simulation of fluid concepts and student surveys to evaluate how the simulation contributed to their learning experience. Employing the COMSOL simulation on fluid dynamics on simple fluid problems as a part of research exam questions, as can be seen in Fig. 16 to Fig. 21, which show the teaching steps starting with the use of a prepared set of CFD Apps students work on throughout the lectures to be an effective learning way.

The add on the traditional chemical engineering curriculum represented in CFD Apps proved their teaching effectiveness assessed by the evaluation results based on pre-post knowledge and skill experiments, and student survey results to successful learning outcomes and effectiveness of the approach.

APP 1 LAMINAB FLOW RETWEEN TWO PLATES DESIGI APP2 LAMINAR FLOW BETWEEN TWO PLATES DESIGN PROBLEM Part 1 - Prevelocity Profile Imposed PROBLIEN Part 2 - Flat Velocity Profile Imposed

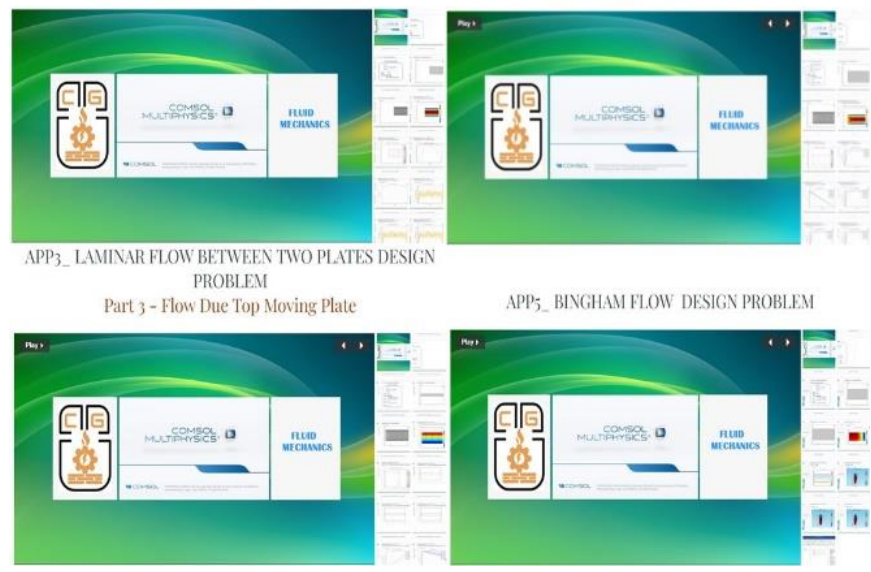

Fig. 16: App1_ Laminar Flow Between Two Plates Pre-Velocity Profile Imposed/ App2_Flat Velocity Profile Imposed/ App3_ Flow Due Top Moving Plate/ App4_Laminar Flow Over 3d Sphere Design Problem.

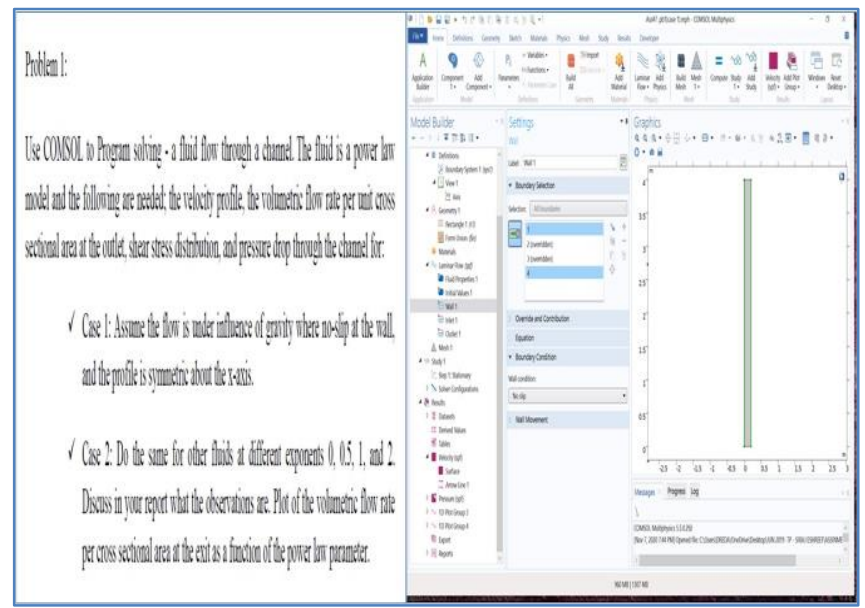

Fig. 17: Advanced Fluid Mechanics Course Final Exam Problem Statement and requested simulation work, and COMSOL Model Student Solution for Final Exam design Problem, Geometry Setting. 


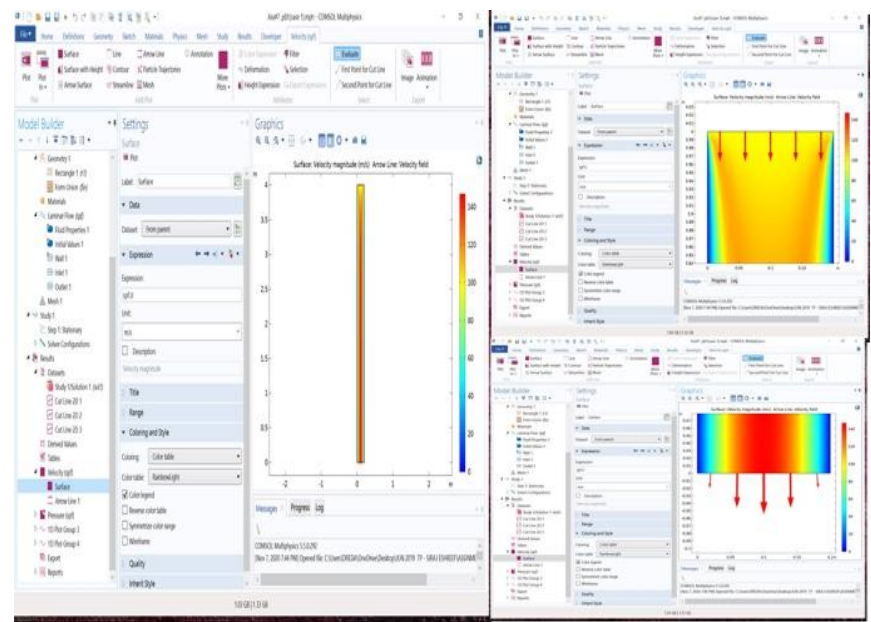

Fig. 18: COMSOL Model Student Solution for Final Exam design Problem, COMSOL Program solving - a fluid flow through a channel, Surface Velocity Distribution

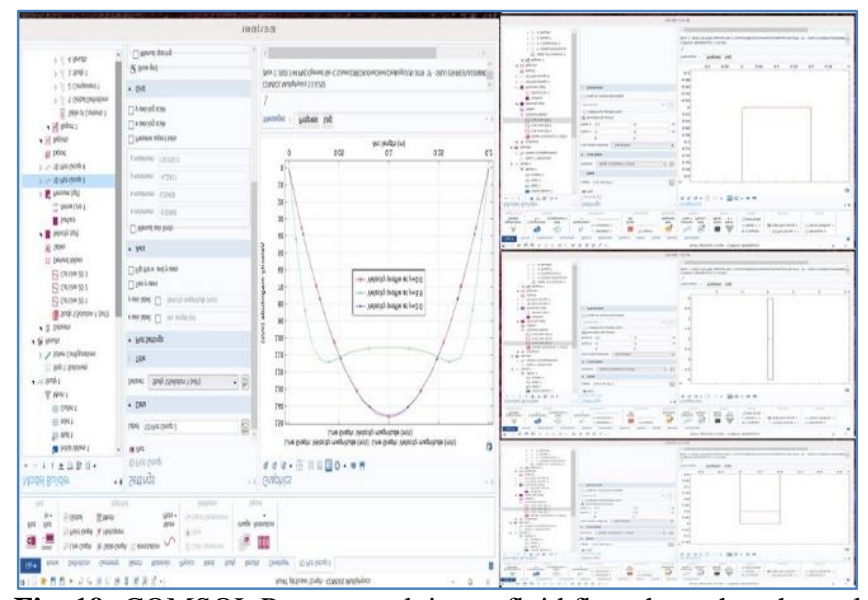

Fig. 19: COMSOL Program solving, a fluid flow through a channel, Velocity Profile at Line Graphs at three different cutlines along the channel.

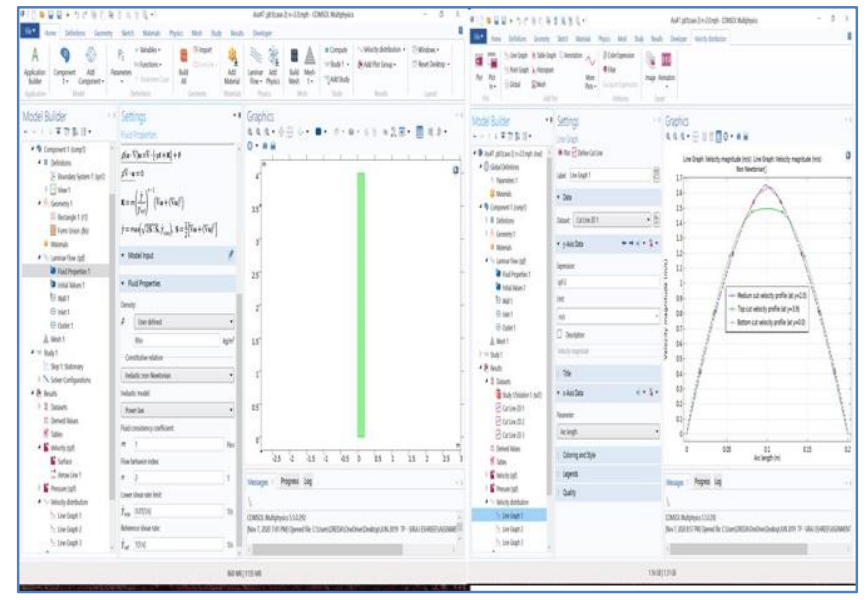

Fig. 20: COMSOL Program solving, a fluid flow through a channel, Case 2, of a fluid at different exponent 2, and Velocity Profile at Line Graphs at three different cutlines along the channel.
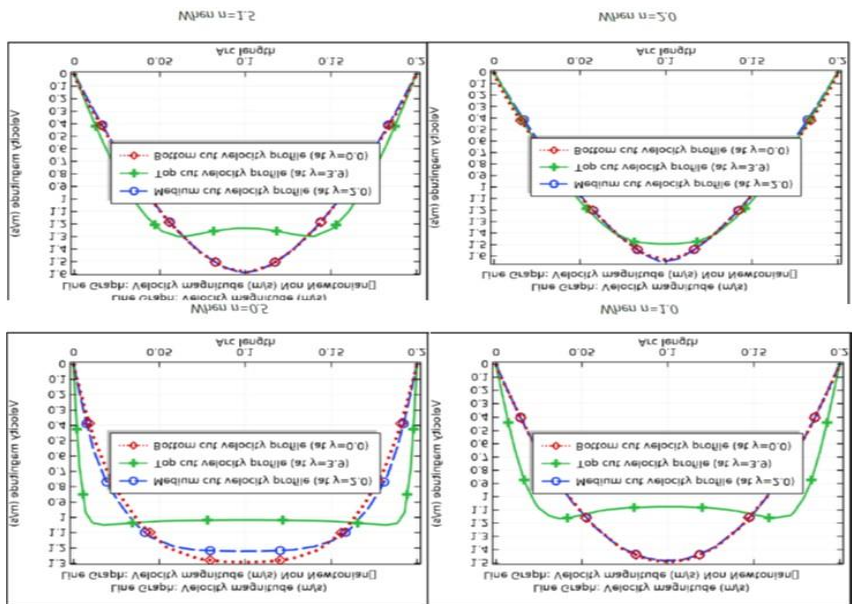

Fig. 21: COMSOL Program solving, a fluid flow through a channel, Case 2, of a fluid at different exponents $0.5,1,1.5$ and 2, and Velocity

Profile at Line Graphs at three different cutlines along the channel.

\section{Advanced Transport Phenomena in Chemical} Engineering Course

Finding new ways to enhance the Advanced Transport Phenomena Course in our department at Elmergib University was one of the tasks followed to improve the curriculum and strategies of teaching the course. Fig. 22 shows the registration part of the postgraduate students to the course into a google classroom as a main step to the arrangement of the learning management system (LMS). Transport phenomena processes, such as fluid mechanics, heat transfer, and mass transfer are crucial to several engineering applications. For postgraduate students who passed successfully the first three advanced courses mentioned above, students were acquainted with partial differential equations and boundary conditions and the use of up to date simulation techniques, this course curricula on transport phenomena will not be challenging. At our chemical Engineering department at Elmergib University, introducing simulation apps to the new engineering curriculum of the advanced courses of separate disciplines of numerical methods, heat transfer, and fluid mechanics helps students gain a deeper understanding of transport processes through visualization. Transport phenomena courses are as difficult to teach as most of the professors would agree and that they are important to graduate students who find it difficult and is not an easy task to translate Fourier's law or Navier-Stokes equations into reallife problems. The associated material properties comprising most transport equations are nonlinear partial differential and integral equations that also often involve complex coupled systems are often a function of temperature, pressure, and several other parameters.

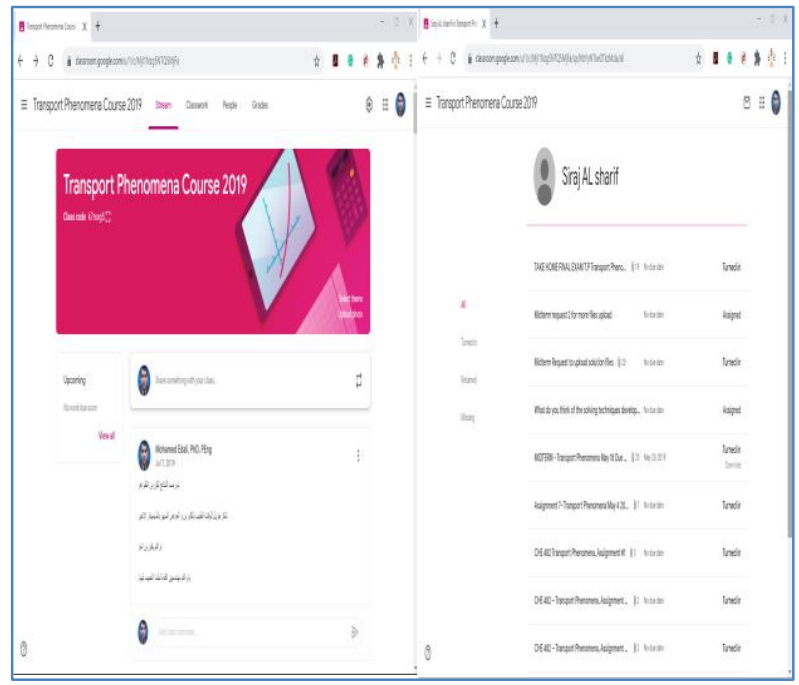

Fig. 22: Advanced Transport Phenomena /Googleclassroom learning management system (LMS) 
In the classroom, students were typically used to learn solving these transport problems by linearizing, approximating, and using accepted assumptions as simplifications. It is well known academically that those approximations are the best way of developing a basic understanding of solving numerical problems. The solutions are erroneous due to those simplifications where and it is normally impossible to even estimate the magnitude of the error without any external empirical data from real-world applications, and that is considered problematic. As can be concluded by looking at Fig. 23 to Fig. 30, COMSOL Multiphysics software proved the ability to couple multiple physics, adding custom materials, and define the complex domain and boundary conditions in order to result in a simple solution representing a focus on the actual physical processes. Through the course work, real-life research questions in some cases, conducting virtual demonstrations and numerical experiments using simulation tools is low risk; quick; and provides a more attractive visual medium than a physical experiment.

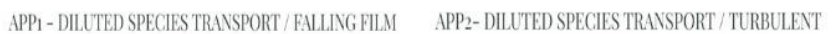
DESIGN PROBLEN FLOW DESIGN PROBLEM
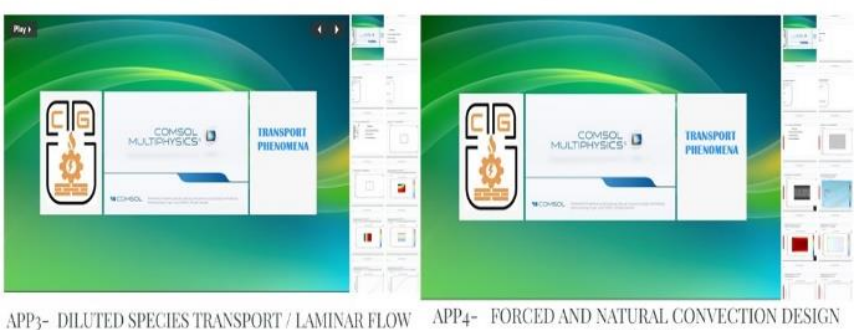
PROBLEN
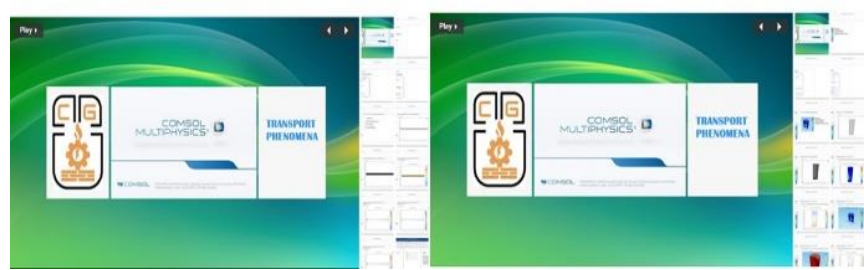

Fig. 23: App1- Diluted Species Transport / /App2- Diluted Species Transport / Turbulent Flow/App3- Diluted Species Transport/ Laminar Flow Design Problem, / App4- Forced and Natural Convection Design Problem

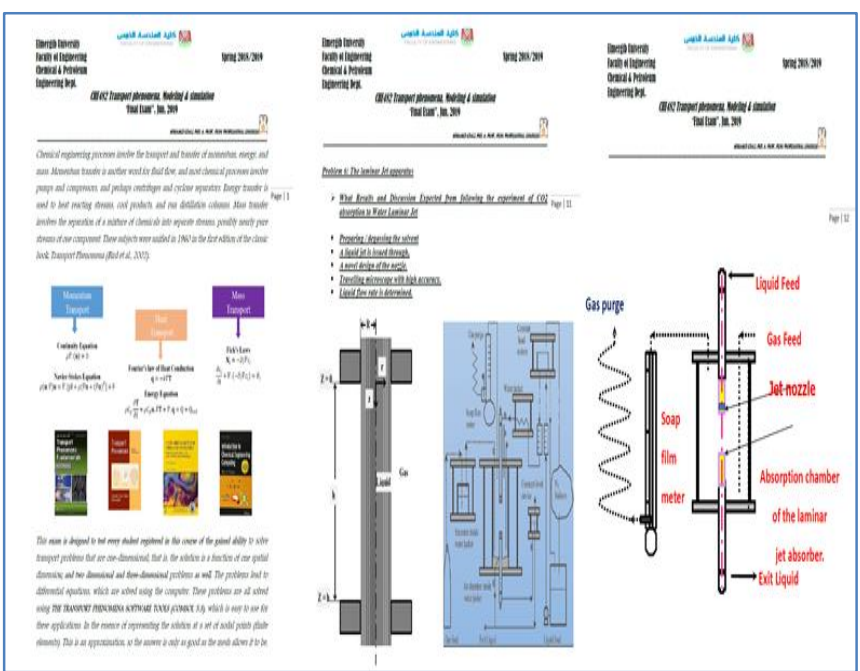

Fig. 24: Advanced Transport Phenomena Course Final Exam Problem Statement and requested simulation work, results and discussion expected from following the experiment of $\mathrm{CO}_{2}$ absorption to Water Laminar Jet.

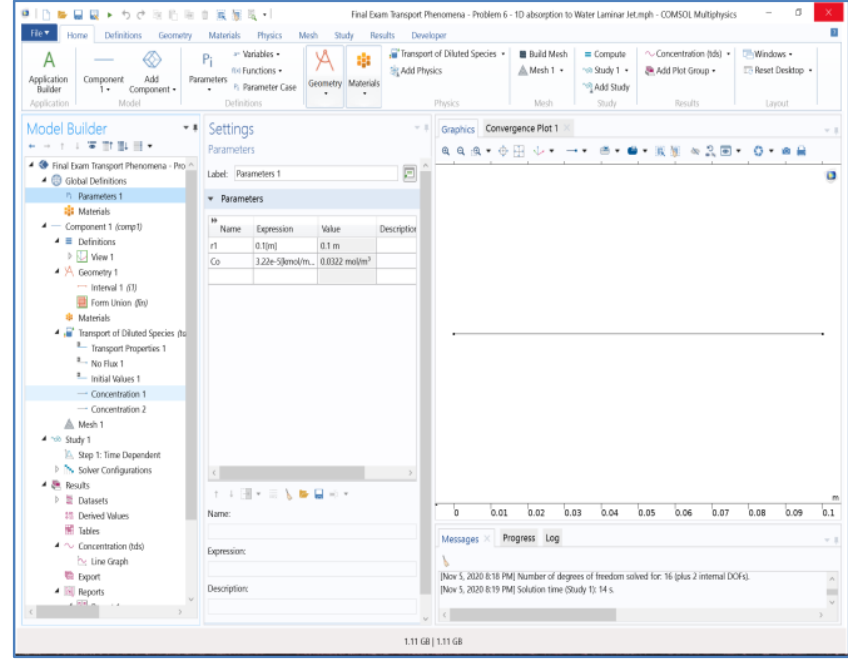

Fig. 25: Final Exam Problem Statement and requested simulation work, and COMSOL Model Student Solution for Final Exam design Problem, Geometry Setting at 1D.

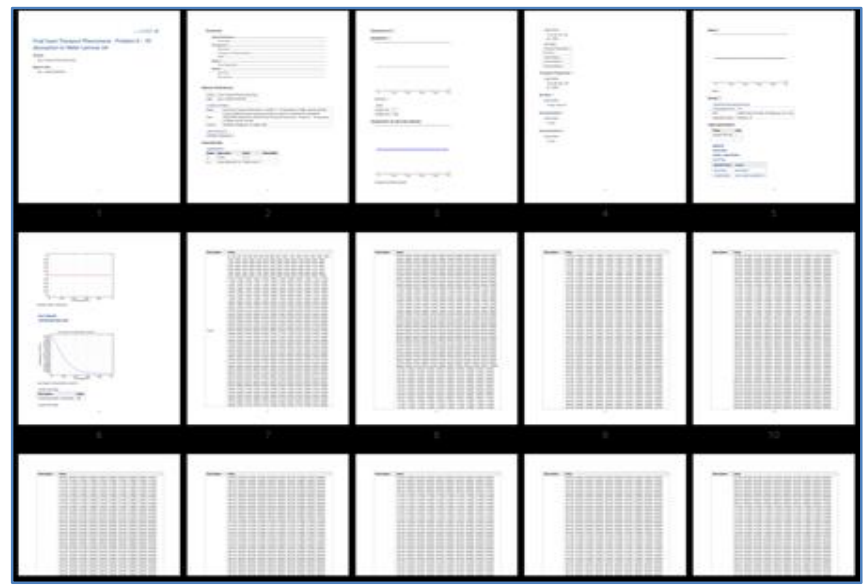

Fig. 26: COMSOL Model Student Solution for Final Exam design Problem Report

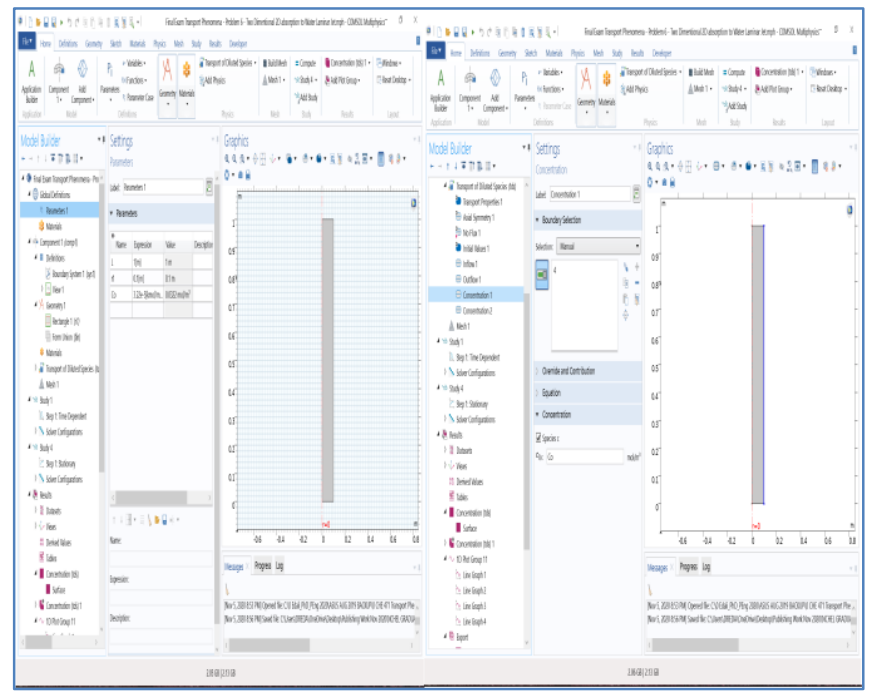

Fig. 27: Final Exam Problem Statement and requested simulation work, and COMSOL Model Student Solution for Final Exam design Problem, Geometry Setting at 2D. 


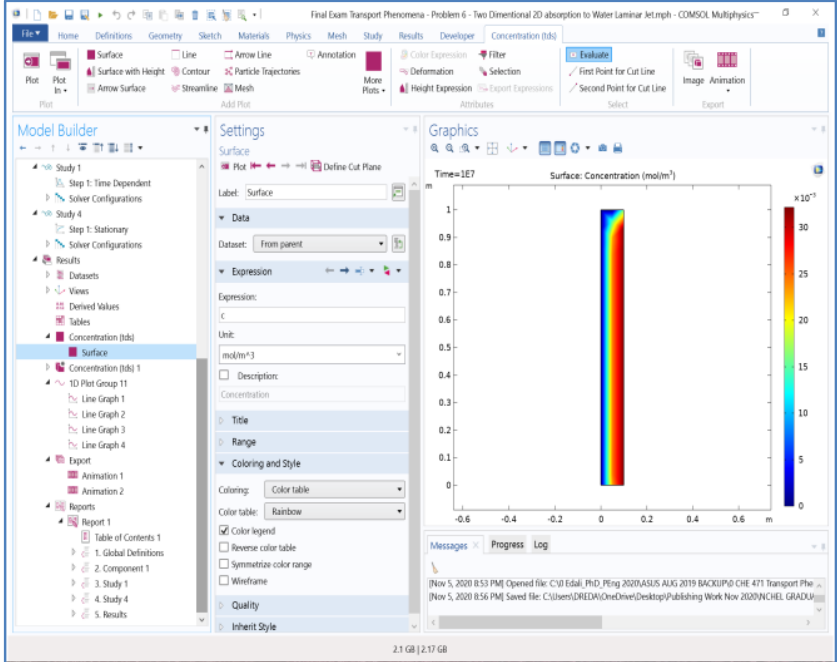

Fig. 28: Final Exam Problem Solution of $\mathrm{CO}_{2}$ absorption to Water Laminar Jet Transport Diluted

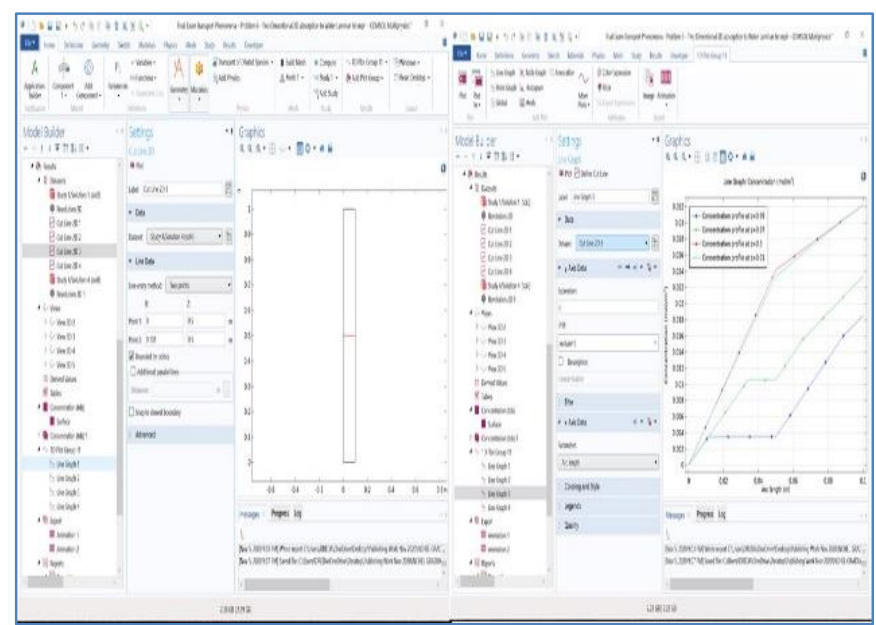

Fig. 29: Final Exam Problem Solution of $\mathrm{CO}_{2}$ absorption to Water Laminar Jet Line, Concentration Distribution Line Graphs at three different cutlines along the domain.

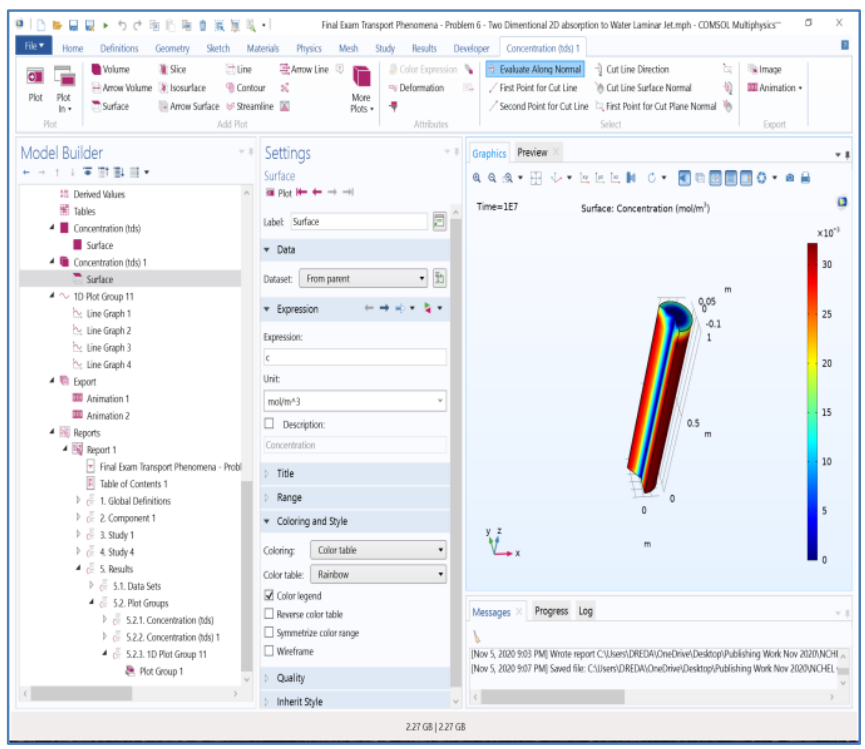

Fig. 30: Final Exam Problem Solution of $\mathrm{CO}_{2}$ absorption to Water Laminar Jet Line, Concentration Distribution Line Graphs at threeDimensional domain.

\section{Conclusion}

This paper contains practical suggestions and references for implementing a unified strategy for teaching simulation to their postgraduate students, starting early in the master's program and continuing in subsequent courses. We believe that simulation packages are a fundamental tool for future chemical engineers. The postgraduate graduate chemical engineering curriculum at our institution Elmergib University has proven the teaching efficiency using both problem-based and project-based learning components. The complex methodology inquiry-based learning has been proven too well prepare a postgraduate student for a successful career in engineering. The new curricula incorporated into a simulation-based design in four successive graduate courses: Advanced computational Numerical Methods, Advanced heat transfer, Advanced fluid mechanics, and Advanced transport phenomena developed technical competency by developing modeling simulation skills. Practical suggestions and references are concluded in short in this paper for implementing a unified strategy for teaching simulation to postgraduate students, starting early in the program, and continuing in subsequent courses. Authors believe that simulation packages are a fundamental tool for the future of a chemical engineer. Finally, with only the efforts of staff, with a wide range of academic, industrial, and lab experience which mirrors the wide-ranging background and experience of engineers, the program can be achieved, and that graduates will work within future roles.

\section{Acknowledgment}

The instructors and authors team wish to thank Professor Elkamel of Waterloo university for his academic and financial support. Creativity Group efforts are appreciated to collect all teaching Apps details and their time of producing most of the Apps formats and their representations into the teaching company website showed in the reference part of this paper. Going over their Apps and teaching techniques presentations on their two websites as shown in [13], which will give more vision to any professor and postgraduate student to go deeply into the proposed teaching project.

\section{References}

[1]- Friedman, T. L., The World is Flat: A Brief History of the Twenty-First Century, Farrar, Straus, and Giroux, 2005.

[2]- Novak, J.D. (1977). A Theory of Education. (Cornell University Press, Ithaca, NY).

[3]- Streveler, R.T., Litzinger, T., Miller, R. and Steif, P. (2008). Learning conceptual knowledge in the engineering sciences: overview and future research directions. Journal of Engineering Education, 97: 279-294.

[4]- Edali, M., Sahem, Z., Ben Rajeb, F., Elkamel, A., "The Use of Application Builder \& COMSOL Multiphysics as a Tool to Build and Deploy Simulation Apps for Heat Transfer". iictcHawaii / USA2017 -The International Conference on Technology in the Classroom, Hawaii-USA

[5]- Sahem, Z., Edali, M., Ben Rajeb, F., Elkamel, A., "The Transport Phenomena Course Teaching Strategies using COMSOL Simulation Apps for Engineers and Scientists". IICE Hawaii / USA2017 / IICE-33493. The International Conference on Education, Hawaii-USA

[6]- Edali, M., Sahem, Z., Ben Rajeb, F., Alaswad, W., Bseibsu, A., Elkamel, A., "Fluid Mechanics Phenomena Class Computational Apps for Engineering Students." Albahit journal of applied sciences 2 (2021), 46-53.

[7]- Culver, R. S., Woods, D., Fitch, P., "Gaining Professional Expertise Through Design Activities," J. Engr. Education, 80, 533-536, 1990

[8]- King, P. M. and Kitchener, K. S., Developing Reflective Judgment, Jossey-Bass Publishers, San Francisco, 1994.

[9]- Felder, R. M., and Brent, R., "Learning by Doing," Chem. Engr. Education, 37 (4), 282-283, 2003.

[10]- Felder, R. M., and Brent, R., "The Intellectual Development of Science and Engineering Students. Part 1. Models and Challenges," J. Engr. Education, 93 (4), 269-277, 2004. 
[11]- Millis, B. J., and Cottell, P., Cooperative Learning for Higher Education Faculty. Phoenix: American Council on Education and Oryx Press, 1998.

[12]- Chapman, C., A Good Idea But It Might Not Work, The NEA Higher Education J. Thought \& Action, 135-136, 1998.
[13]- Creativity Group Technical Services websites, https://zsohim.wixsite.com/cgts-ca/multiphysics-simulation, https://maedalien.wixsite.com/dredali. 